\title{
PROBLEMAS DO ENSINO DA LITERATURA: DO PERIGO AO VOO POSSÍVEL
}

\author{
Giselle Larizzatti Agazzi \\ gisellelarizzattiagazzi@gmail.com
}

\section{CONSIDERAÇÕES INICIAIS}

Os problemas sobre a formação do leitor de textos literários são inúmeros e têm se adensado nos últimos anos. A reflexão proposta sobre esse amplo e complexo panorama da educação literária se dá em torno das polêmicas que acompanharam a publicação dos documentos oficiais - PCN, PCNEM e Orientações Curriculares Nacionais -, expressas em "Literatura", de Enid Yatsuda Frederico e Haquira Osakabe (2004). A discussão percorre alguns dos questionamentos de Rildo Cosson (2009), Graça Paulino (2002) e Todorov (2009), quando se debruçam sobre as práticas pedagógicas desenvolvidas nas últimas décadas, fazendo reverberar vozes e letras tão antigas como as da professora Lígia Chiappini, ao publicar já em 1983 Invasão da catedral: literatura e ensino em debate, em que faz um balanço crítico da ação - perniciosa - do governo ditatorial na educação literária dos jovens e na formação inicial dos professores.

A perspectiva assumida é a de que há um progressivo afastamento entre o público e as obras e que ele acontece, ironicamente, por meio das relações entre literatura e ensino. Vê-se nos espaços acadêmicos a preocupação com a história e as correntes literárias, a biografia dos escritores, as fortunas críticas e não com a leitura dos textos literários. Nesse contexto, a literatura, para falar com Todorov (2009), fica em perigo, porque colocada dentro de um círculo vicioso: os professores vivenciam 
cada vez menos o texto literário e, com isso, suas práticas são cada vez menos empenhadas na formação do leitor literário.

O empobrecimento da educação literária revela-se como um impasse de difícil superação, tratado aqui como um eixo em torno do qual se desdobram os problemas do ensino da literatura. Trata-se da formação inicial e continuada docente, que pouco avançou nos últimos anos no que diz respeito à formação dos leitores literários. A aposta é a de que professores com experiências literárias vivas transformam gradativamente práticas pedagógicas assumidas no cotidiano escolar.

Como caminho para mudar radicalmente as atuais práticas pedagógicas, a abordagem vai ao encontro do olhar construído por Benjamin Abdala Jr. (2002), para quem o ensino das literaturas de língua portuguesa deve encontrar novos rumos, novos "voos" e procura sugerir práticas pedagógicas que a esses se dirijam.

\section{A leitura e o ensino da literatura}

Se a educação literária se constrói ao lado da formação de leitores de modo geral, uma vez que não há como acessar o universo da palavra artística se não houver iniciação no universo da leitura, refletir sobre hábitos leitores no Brasil pode ser um interessante ponto de partida para pensar as relações entre literatura e ensino.

Dentre os muitos dados divulgados sobre hábitos leitores, chama atenção a pesquisa "Retratos da Leitura no Brasil" (2011), porque, estando na sua terceira edição (a primeira foi realizada em 2001), pode apresentar um olhar diacrônico sobre o entendimento que as pessoas têm da importância do ato de ler e sobre as práticas leitoras que elas desenvolvem. Coordenada pelo Instituto Pró-Livro e realizada pelo IBOPE, o arco temporal entre a primeira e a última pesquisa sugere algumas hipóteses (pelo Instituto, formuladas como conclusões gerais), as quais inquietam até mesmo os espíritos mais otimistas, porque contestam as políticas públicas relacionadas à formação de leitores.

Surpreendentemente, os resultados obtidos revelam que o livro é sim muito valorizado, sendo visto por sessenta e quatro por cento dos entrevistados como "fonte de conhecimento para a vida" (Pró-livro, 2011, p. 43); também sessenta e quatro por cento concordam com a afirmação de que "ler bastante pode fazer uma pessoa 'vencer na vida' e melhorar a sua situação socioeconômica” (Pró-livro, 2011, p. 44). Apesar da expressiva porcentagem dos entrevistados que valoriza a leitura, a média de livros lidos por habitante não chega nem a dois $(1,85 \%)$. As pesquisas, vistas em conjunto, apontam ainda para uma sensível queda 
no número de livros completos lidos pelos entrevistados (em 2007, eram quase dois livros e meio).

Na prática, ocorre que as pessoas cada vez leem menos, apesar de valorizarem cada vez mais a leitura como fonte de conhecimento e meio de ascensão social. A ironia não poderia ser maior, ainda mais com o reconhecido crescimento editorial. Para finalizar, vale ressaltar da pesquisa que continua a persistir uma relação direta entre hábitos leitores e classe social, escolaridade e ambiente familiar: "Quanto mais escolarizado ou mais rico é o entrevistado, maior é a penetração da leitura e a média de livros lidos nos últimos 3 meses" (Pró-livro, 2011, p. 102)

Para a comunidade interessada em refletir sobre o ensino da literatura, tais informações aprofundam os impasses em que se encontram os professores ea educação literária das crianças e jovens. A questão levantada por Lígia Chiappini (1983), quando refletia sobre o ensino da literatura ao longo do período ditatorial permanece atual: os professores não leem e, com isso, não se formam como leitores. Pensando em educação literária, é no mínimo empobrecedor desprezar essa que seria a responsabilidade dos ambientes escolares e acadêmicos de permanentemente desafiarem o público a desenvolverem habilidades e competências fundamentais à formação do homem.

Se as pessoas leem cada vez menos, como ganhar o interesse dos alunos para a leitura dos textos literários em ambientes escolares que privilegiam a história literária, a biografia dos escritores, os aspectos de teoria literária, impedindo os alunos de usufruírem da genuína experiência literária? O que pensar do professor em formação inicial, ingressante nos cursos de Letras e de Pedagogia, cuja experiência literária tem sido restrita pelas prioridades curriculares que selecionam as mediações textuais e não os textos? Como lidar com a seleção das obras a serem lidas e trabalhadas em sala de aula? Qual é, enfim, a concepção de literatura que tem pautado a formação dos professores de literatura?

Em contextos em que a cultura aparece entre os bens de consumo e entra como mais uma mercadoria, a ser logo descartada e desprezada por quem a usou, a literatura se torna motivo de inquietação. Em princípio, a constatação de que as obras são procuradas basicamente para saciar o desejo de prazer poderia ser um começo de conversa. Mas só um começo, porque, diante da fundamental lição de Candido (1972) de que a função da literatura está na sua capacidade de "humanizar" as sociedades, a noção de literaturamercadoria não contempla, definitivamente, os alcances que a arte literária tem na vida social: "Não nos cabe senão compreender resistindo e resistir compreendo", diz Bosi (2002, p. 254), para estabelecer a perspectiva de que a função da literatura está no exercício pleno da memória, que se volta 
para a tradição ao mesmo tempo em que atualiza as "formas libertadoras e contraditórias da modernidade" (2002, p. 254).

Ativando a memória da tradição, que trabalha no passado, e a consciência profunda da matéria contraditória de que somos feitos, a literatura alcança a sua função mais genuína ao possibilitar a experiência dinâmica da história em diálogo com as subjetividades. A humanização está nesse jogo, ativo e perturbador, proporcionado pela experiência literária, que coloca em atrito a memória coletiva e a individual ao aproximar o sujeito do texto literário.

Apesar de repetidas à exaustão algumas das "bandeiras" de Paulo Freire (1989), elas ainda parecem revolucionárias, quando aproximadas do ensino de literatura: "A leitura do mundo precede a leitura da palavra, daí que a posterior leitura desta não possa prescindir da continuidade da leitura daquele. Linguagem e realidade se prendem dinamicamente" (1989, p. 9). Como mostra Ezequiel Silva (2002), para quem a prática leitora depende da apreensão, apropriação e transformação dos significados do texto, essa perspectiva aponta para a necessidade de que o leitor adquira uma postura ativa diante do texto, procurando deslindar seus múltiplos sentidos.

A compreensão, continua Silva, não é um processo puramente racional, porque depende do envolvimento emocional do leitor com a obra e das construções sociais que envolvem a cadeia de sentidos: o diálogo entre a subjetividade daquele que lê e o quê a obra comunica em forma e em conteúdo promove a aproximação entre o universo do leitor e o veiculado pela obra. Dessa aproximação, surge o lugar onde acontece a experiência literária e onde ocorre a formação e a transformação do público leitor.

\section{Práticas pedagógicas}

Não é possível contar para um aluno do segundo ano do Ensino Médio o "Poema em linha reta”, do Álvaro de Campos. É claro que explorar a personalidade abissal de Fernando Pessoa em sala de aula poderá ser uma boa estratégia para seduzir o público adolescente, afinal, é nessa faixa etária que a vileza e a hipocrisia da sociedade começam a incomodar. Mas é só uma estratégia de aproximação. A leitura do "Poema" é que poderá gerar o impacto, a ruptura, a possibilidade de transformação da subjetividade e de ampliação do horizonte de expectativas dos alunos. Entretanto, como o professor muitas vezes se tornou especialista na fortuna crítica do autor, como se vê nas pesquisas realizadas por Chiappini (1983), Paulino (2001) e Leahy-Dios (2004), a prática de desenvolver estratégias de abordagem do texto é substituída pelas discussões teóricas.

Fernando Pessoa, como se sabe, é uma referência obrigatória 
para ser estudado no ensino médio e superior. Se for trabalhada com distanciamento, como se vê nos apressados currículos da educação básica, seu potencial transformador será restrito; o mesmo ocorre no ensino superior, quando a fortuna crítica é privilegiada em detrimento da leitura e discussão dos seus textos. Isso não se deve ao fato de ser a obra de Pessoa um cânone, mas ao modo pelo qual ela é trabalhada. Portanto, não é uma questão de demonizar o cânone, evitando-o. Ao contrário, o cânone só o é, enquanto comunicar algo para a sociedade que o lê. Quando a comunicação cessar, o cânone será substituído. O impasse está, sim, nas estratégias de aproximação entre o leitor e o texto literário, mediado por inúmeras informações extraliterárias.

O trabalho com os textos não-canônicos, por exemplo, os oriundos das literaturas africanas de língua portuguesa, têm recebido tratamento semelhante, apesar de instaurarem perspectivas, a um só tempo, comuns e diferentes do público brasileiro. O que se vê normalmente é que o docente, diante da sua turma de professores em formação, demora-se na apresentação do contexto histórico, das questões teóricas e biográficas, passando muito rapidamente pelo texto. Essa prática, como já mostrava Chiappini em 1983, não é gratuita, pois ao fim o docente está reproduzindo as relações de ensino e de aprendizagem que construiu ao longo do seu histórico escolar.

Como fazer diferente é a pergunta que se impõe. Estratégias comuns para alguns poucos professores do ensino superior como a de promover nas aulas com rodas literárias - em que o grupo se senta em círculo, lê pausadamente uma obra e depois conversa sobre ela - soam para alguns outros como práticas pouco reflexivas. Entretanto, não é o que ocorre, quando o professor em formação se depara, apenas para dar um exemplo, com o "Famigerado" de Guimarães Rosa. As reinvenções morfológicas e sintáticas, o ritmo do texto, as armações literárias constituem os inúmeros níveis de interpretação textual, os quais, se explorados por um grupo de leitores, podem ser deslindados até comunicarem algo para cada subjetividade. Da obra para o coletivo, do contexto original em que foi escrito para o do grupo leitor, da sociedade para o indivíduo, práticas pedagógicas voltadas para a leitura compartilhada, discussão e apreciação do texto em sala deveriam compor parte substancial dos cursos de Letras. Habituando-se a mergulhar no texto e subir à sua superfície para justificar sua leitura para o grupo, o professor em formação poderá construir a autonomia indispensável para se tornar um leitor proficiente, apropriando-se dos meandros textuais a partir de hipóteses construídas e verificadas antes de recorrer a manuais ou textos explicativos.

Se não houver essa vivência autônoma, os sentidos possíveis do texto 
para a subjetividade leitora não serão engendrados. É a construção da teia das interpretações pelo próprio sujeito que movimentará a sua relação com o texto e, para falar com Freire e Silva, com as suas experiências, com o mundo e com a sua subjetividade, garantindo-lhe o lugar de alguém que responde conscientemente ao que lê e ao que sente.

Em infinitos exercícios intertextuais, também a obra se transformará, sendo ela, de um lado, resultado das forças históricas e artísticas que a geraram, e de outro, do contexto de leitura e do seu leitor. O mesmo "Poema em linha reta” não será lido igualmente por aqueles que se aproximaram de A máquina de fazer espanhóis, romance em que o autor, Valter Hugo Mãe, apropria-se dos sentidos de outro poema de Álvaro de Campos, o “Tabacaria”. Enfeixados os textos em outros contextos, novas perspectivas de leitura surgirão.

Experimentar o desconserto diante do "Esteves sem metafísica", presente na "Tabacaria” e personagem de A máquina de fazer espanhóis, é ainda mais potente do que estudar o contexto histórico modernista ou conhecer a biografia de Pessoa. A leitura do poema e do romance dialogarão com o repertório do público, resignificados e passíveis de resignificarem o texto original, que acumulará outros sentidos e assim permanecerá comunicando renovados universos para além do seu tempo original. Estão aí, para reafirmar a leitura como experiência individual e coletiva, os fenômenos literários, lidos no intenso diálogo intertextual travado entre as obras, que se transformam permanentemente em novosvelhos painéis e paisagens.

Entre a abertura que o ato de ler proporciona e a educação literária, está a responsabilidade dos espaços escolares, onde, como adverte Rildo Cosson (2009), os sujeitos se descobrem como parte da coletividade, pois ao se confrontarem com o outro e com o 'si mesmo'. Esse é o lugar privilegiado em que se deveriam dar, pois, os diálogos entre a memória histórica e a consciência sobre o presente, entre a história da humanidade e a familiar, entre a constituição da identidade nacional e a individual. Ao compartilhar a interpretação dos textos literários no grupo escolar, o aluno pode ampliar os sentidos que construiu previamente, mobilizando o seu horizonte de expectativas.

Na ação de compartilhar interpretações textuais, é possível ganhar consciência de que a coletividade fortalece a individualidade, exatamente, porque pode ampliar a visão que uma pessoa tem do mundo, de sua intimidade, dos textos literários.

Se o ato de ler é compreendido dentro do jogo dialético, entre o eu e o outro, entre o horizonte de expectativas estabelecido e o que está por vir, entre o autor e o leitor, entre o estudante e o ambiente escolar, é importante 
reconhecer que a leitura é uma prática constitutiva da aprendizagem que permeia todas as áreas do conhecimento de forma não segmentada. A leitura do texto literário promoverá, nesse contexto, a dinamização desse jogo dentro de um espaço em que a palavra polissêmica, os recursos estilísticos, formais, a construção inesperada do texto em arranjos e sentidos inesperados poderão provocar o estranhamento no leitor. Eis aqui a especificidade de maior relevância que domina o lugar em que se engendra a literatura.

Não vale muito, dentro dessa concepção, conceituar a literatura, os gêneros literários, descrever movimentos literários e biografias de autor. Tais informações não apontam para as especificidades do texto literário. Para provocar o estranhamento, é preciso submergir em um mundo estético e ético diferente do que o leitor frequenta.

Os percursos não são fáceis, ainda mais quando tecemos um olhar retrospectivo sobre a história do ensino da literatura no Brasil. Ao fim, o que provocou o atual quadro do ensino da literatura vem anunciado e explicado por Chiappini (1983), quando advertia para o fato de que, herdeiros das práticas ditatoriais, os professores perderam a liberdade e a autonomia diante do texto literário. Os resultados são os livros didáticos sempre acompanhados por longos manuais com as respostas esperadas para a interpretação de um ou outro conto, poema, fragmento de obra.

Reconhecer que a leitura é um processo cognitivo e perceptivo implica reconhecer que as práticas leitoras interagem com o leitor tanto no que diz respeito ao seu repertório (passado) quanto à sua experiência (presente) e à expectativa de vida que tem (futuro). A confluência dos tempos gera uma ação cujo caráter interacionista da linguagem coloca o leitor e o texto em permanente diálogo com a coletividade. Afirmam os Parâmetros Curriculares Nacionais de Língua Portuguesa:

O aluno é um ser humano completo, inserido em ambientes socioculturais diversos, que constrói conhecimentos na interação com seus pares e com o meio em que vive. (...) A aprendizagem dá-se pela ação do aprendiz sobre o que é objeto de seu conhecimento e é potencializada por ambientes favoráveis. A atividade em parceria - em que os papéis do parceiro experiente e do aprendiz se alternam - é de grande importância para a aprendizagem. (...) A reflexão é condição de aprendizagem da língua: é preciso pensar sobre como se pode ler e escrever quando ainda não se sabe fazê-lo. A língua realiza-se no uso, nas práticas sociais. A finalidade principal do trabalho com a Língua Portuguesa na escola é a formação de usuários competentes da linguagem, o que deve estar, por sua vez, a serviço do desenvolvimento dos alunos como pessoas e como cidadãos. (...) Saber decodificar letras em sons e codificar sons em letras não significa ser capaz de utilizar a língua: a capacidade de uso é equivalente à possibilidade de falar, escutar, escrever e ler em diferentes contextos de comunicação. (PCN, 1998, pp.82 a 84)

Nem a simples decodificação - como queriam os estruturalistas, 
para os quais a compreensão e a interpretação dependem apenas do texto (e cujas implicações para o ensino da literatura são as perguntas sobre a obra de caráter imediatista) - nem o foco no leitor - em que dele exclusivamente depende a interpretação do texto (e cujas implicações para o ensino da literatura são as perguntas sobre a obra de caráter intimista) - podem iluminar as várias operações que se dão na experiência literária, vivida entre os diversos níveis (superficial, intermediário e profundo) de interpretação textual. Tem-se, assim, uma concepção do ensino da língua segundo os seus usos sociais. Mas e o ensino da literatura?

Segundo críticos como Graça Paulino (2002), os documentos oficiais publicados pelo MEC significaram, em um primeiro momento, um profundo "descaso" do poder público com o ensino de literatura, uma vez que eles não garantiam a reflexão sobreas especificidades do texto literário e, mais do que isso, não estimulavam a formação inicial e continuada docente, pautadas na experiência literária. Mais contundentes ainda foram as críticas de Enid Yatsuda e Haquira Osakabe (2004) feitas aos Parâmetros Curriculares Nacionais para o Ensino Médio (2002) no que diz respeito às relações entre ensino e literatura, exatamente, porque, segundo os autores, eles traziam um tratamento genérico do texto literário e apontavam para o descompasso entre as práticas adotadas em classe, as expectativas dos alunos e a formação dos professores. Surgiram dessa lacuna as Orientações Curriculares para o Ensino Médio (2006), que procuraram estabelecer um olhar mais adequado para o ensino de literatura. A participação de Enid Frederico, Haquira Osakabe e Lígia Chiappini Moraes Leite nas discussões iluminam aspectos do ensino de literatura e apontam para políticas direcionadas à formação do leitor literário. Novas orientações para problemas tão antigos quanto contemporâneos. Se as Orientações representaram um avanço no que diz respeito à discussão em torno do ensino de literatura, na prática, pouco ou nada mudou. Os estudiosos evidenciaram a especificidade, a complexidade e a autonomia do componente curricular, mas a luz projetada nos problemas não impulsionou mudanças nos cursos de Letras e, menos ainda, na educação básica.

Ao que indicam os documentos oficiais publicados pelo MEC e a própria tradição literária brasileira, nada justifica atualmente que o conceito de "cânone" não seja visto de modo flexível e que as estratégias de abordagem do texto literário não se transformem, a não ser a necessidade de encobrir as lacunas nas relações de ensino e de aprendizagem da literatura.

A reivindicação de Sousândrade por parte de Oswald de Andrade 
como texto canônico da nossa literatura é apenas um exemplo desse caráter mundano, temporal, histórico do cânone. Graça Paulino, em entrevista concedida em 2010, é categórica ao afirmar que os professores têm prestado um "deserviço" ao Brasil no que diz respeito ao ensino da literatura. Segundo Paulino, os professores são "despreparados" e, por isso, indicam as obras canônicas sem sequer questionar a possibilidade de, em lugar delas, apresentar textos que de fato interessassem para seu público. O resultado, para a pesquisadora, é que os alunos continuam a ver a literatura como algo chato.

É preciso deixar claro que o problema não são os cânones - se um livro não comunica nada a seu público-alvo, não pode ser lido como cânone; essa é a concepção adotada desde o início da discussão proposta. O problema é que, não usufruindo de autonomia no universo literário, o professor muitas vezes segue de modo acrítico (2010) os conteúdos programáticos previstos e não seleciona outros materiais ou práticas.

Os livros didáticos indicados pelo MEC, com raríssimas exceções, não fazem diferente, mesmo diante de uma lei como a 11.645/o8, que torna obrigatório nas escolas básicas o estudo da cultura negra e afrodescentente. Teoricamente, tal lei deveria motivar a revisão das práticas pedagógicas relacionadas ao ensino de literatura em sala de aula, uma vez que põe em pauta a necessidade do olhar comparado. Isso, em termos teóricos, seria romper com a historiografia tradicional, descritiva e positivista. Afinal, a inclusão de, por exemplo, "A carta", uma narrativa curta de Mia Couto, deveria promover um momento de leitura dela. Esse momento poderia constituir-se como privilegiado, porque poderia significar um mergulho dos alunos em um universo estranho ou pelo menos em uma maneira diferente deabordar o texto, mobilizando-oa pensar nos sistemas literários de outro ponto de vista, o africano. Mas não é o que tem ocorrido, porque o próprio livro didático impede a experiência da tensão, das contradições, colocando o texto dentro dos padrões já estabelecidos para o estudo da literatura brasileira e portuguesa, ampliando ainda mais a quantidade de conteúdos a serem absorvidos.

Desse modo, mesmo quando os alunos entram em um mundo completamente estranho, isso se dá de modo completamente igual, o que aborta a possibilidade de mergulhar na diferença, o que seria possível tão somente com a leitura e a exploração do conto enquanto objeto estético e provocador, dinâmico e polissêmico. O estranhamento é aplainado tornando-se algo parecido com o que já se conhece por aquele que acaba de descobrir um novo universo. Não se conquista, assim, a brecha necessária para mudanças. Nada menos literário do que isso.

As Orientações Curriculares Nacionais para o Ensino Médio, como 
assinalado, enfatizam que as unidades escolares têm autonomia para decidirem como tratar a literatura em sala de aula e quais obras indicarem para leitura. Ora, se o MEC admite a autonomia das escolas com relação ao ensino de literatura, se os documentos oficiais dão liberdade para os professores escolherem obras que comuniquem algo ao público-alvo, talvez seja o momento de valorizar a fala de Graça Paulino e investir tempo e energia para mudar as práticas pedagógicas adotadas na formação inicial e continuada docente.

\section{A “literatura em perigo" e o "voo possível”}

A literatura como componente curricular tem gerado, pois, o afastamento entre o leitor e o texto literário. Ironicamente, a escola tem contribuído para que os alunos desgostem das obras, o que se aprofunda substancialmente no ensino médio. Há problemas de diversas ordens que atravessam a relação dos adolescentes com as obras literárias, a começar por questões econômicas e sociais (2011), mas a escola deve estar preparada para lidar com a realidade do seu público, o que apenas acentua o investimento na formação de professores críticos e criativos.

Contraditoriamente, o mercado promove inúmeros textos literários, lidos muitas vezes dentro da chamada "literatura marginal", que hoje, como se sabe, pouco diz, dado que diversos grupos periféricos reivindicam seus lugares centrais no panorama cultural contemporâneo. Apesar dessa transformação de perspectivas, como já apontado nos estudos relativos às literaturas africanas de língua portuguesa, continua a predominar o ensino dos textos amparado no paradigma positivista, para o qual prevalece a historiografia literária, o modelo sistematizado e descritivo. Esse modelo, que Leahy-Dios descreve depois de exaustiva pesquisa em diversas escolas brasileiras (2004), exige dos alunos do ensino médio - e superior - grande quantidade de conteúdo, mas pouca reflexão.

Para romper com tal círculo vicioso, é necessário, de um lado, o alargamento e o aprofundamento da concepção de cânone, a qual sustente a seleção por parte do docente de obras que dialoguem com seu públicoalvo (o que não significa abolir Camões, Pessoa, Graciliano Ramos, mas sim inverter o ponto de partida das práticas pedagógicas, chegando até mesmo a, por exemplo, Vidas Secas, mas porque o repertório dos alunos, seus anseios, os conflitos sugeridos em classe parecem se aproximar do universo literário que a obra veicula); e de outro, a construção de estratégias para o modo de tratar os textos literários, o que traz uma relativização da apresentação descritiva da historiografia literária e a incorporação de práticas leitoras por meio de rodas literárias, discussões, trabalhos em grupo, leituras silenciosas e compartilhadas em sala.

Tal proposição significa, em última análise, refletir sobre os modelos 
de história literária: a valorização das obras se dá pela qualidade delas dentro de um determinado contexto? Ou pelos contextos exteriores a elas? Essa dicotomia, como evidenciam os estudos literários, não é nova e define os contornos das abordagens formalistas ou historicistas.

Segundo Alfredo Bosi (2002), dois estudos críticos procuraram uma "saída feliz" para essa problemática: a História da literatura ocidental, de Otto Maria Carpeaux, e Formação da literatura brasileira, de Antonio Candido:

\footnotetext{
Carpeaux e Candido valem-se estrategicamente da categoria de classe na medida em que lhes serve de âncora para fixar mais firmemente as produções simbólicas na vasta plataforma da infraestrutura de uma nação. Mas essas categorias não se impõem com um sentido econômico imediato, nu e cru. É a cultura, teia espessa de valores vividos, pensados e estilizados que dá a ambos a necessária mediação entre a realidade ampla e genérica da sociedade de classes e o trabalho singular da expressão artística. (BOSI, 2002, p. 33)
}

Bosi ressalta o olhar dialético de ambos os críticos, repetindo a frase tomada de Candido de que "quem quiser ver em profundidade tem de aceitar o contraditório, nos períodos e nos autores", porque, segundo uma frase justa, ele "é o próprio nervo da vida" (BOSI, 2002, p. 51). A literatura como disciplina escolarizada não se orienta à moda dialética de Candido ou Carpeaux. Ao contrário, segue as primeiras histórias literárias brasileiras, então organizadas segundo critérios cronológicos e políticos, geralmente, ligados a projetos de afirmação da identidade nacional.

Leahy-Dios (2004) chama a atenção para o fato do estudo da disciplina de literatura desde o século XIX manter um caráter historicista nacionalizante, o que provocou a dissociação entre ler e estudar literatura. Com isso, continua a autora, perpetuou-se a desvalorização da educação literária nos currículos e a manutenção do perfil historiográfico dos estudos literários, levando ao tratamento acrítico do cânone.

A perspectiva histórica sobre o ensino da literatura não deveria trabalhar contra a formação de leitores literários; ao menos teoricamente, as duas perspectivas não deveriam ser excludentes, como se lê na História da Literatura Brasileira, de Alfredo Bosi, cujo esteio se fez da historicidade do ponto de vista de convergências estilísticas (ainda que, como quer Candido, autores coetâneos possam dialogar em torno das convergências por negá-las).

Com um currículo orientado para as literaturas de língua portuguesa, seja na educação básica ou nos cursos superiores, a orientação de Bosi poderia servir para ampliar e aprofundar os horizontes dentro da sua proposta de "historicismo renovado": um olhar profundo sobre as 
especificidades da obra, no seu jogo e construção, em íntimo diálogo com a ideologia, a sociedade, as contradições do período que a gerou.

$\mathrm{Na}$ esteira do que propõe Bosi, o estudo de Benjamin Abdala Júnior em "História Literária e o Ensino das Literaturas de Língua Portuguesa" (2003) pode contribuir significativamente para a transformação das práticas pedagógicas, porque questiona a própria concepção de ensino de literatura. O professor e crítico, um dos fundadores da Ârea de Estudos Comparados da USP, retoma a ideia já proposta por Candido e Bosi de que a história literária é feita de impactos e de que esses devem ser valorizados e, não, anulados como acontece atualmente. Afinal, continua Benjamin, a história literária vale por seu caráter conflituoso, uma vez que garante o permanente deslocamento de olhar. Essa forma de impacto é necessária à formação plena do aluno:

\footnotetext{
Na escolha de motivos históricos, repetimos, preocupamo-nos com o impacto, com a forma que repercutiu num dado momento e se abriu para o depois. São impactos que nos caracterizam os códigos dominantes num período ou a emergência de outros, dentro do complexo conflituoso da configuração histórica. O estruturalmente dominante num momento pode não o ser noutro; pode entretanto voltar num tempo futuro não como simples repetição, mas como um campo transformado de matérias vivas, de momentos vários. (ABDALA, 2003, p. 36)
}

A percepção da história da literatura pode ser plural, quando recoloca o olhar dialético sobre os estudos literários, acentuando a tensão entre as polaridades, entre o que há e o que poderá ser, entre a acomodação e o imponderável, entre a realidade e o devir. É certo que o professor de literatura reivindicará uma ordem nesse caos, dadas as necessidades didáticas. Entretanto, ao assumir a segmentação da história da literatura, o professor pode questioná-la a partir da leitura de textos literários divergentes, evitando, assim, a "atomização" do período, das correntes, dos movimentos e das tendências.

Aos professores em formação inicial caberá a compreensão de que a normatização das escolas dentro de períodos lineares e descritivos, segundo um olhar positivista e hierárquico, não passa de um recurso didático hoje em dia pouco útil, quando se pensa na necessidade de revitalizar o "impacto" do texto no público-leitor. Aceitar que o conhecimento claro e objetivo da literatura é um artifício pode motivar os professores em formação a buscarem na filigrana do texto literário inúmeras possibilidades de diálogo com o universo veiculado pela obra.

O passado, desse modo, chegaria ao leitor não por "procedimentos 
exteriores", mas por o que Benjamin chama de "experiência internalizada": a comparação entre textos e períodos permitiria ao aluno articulá-los dentro de novos arranjos para, a partir disso, revestir a matéria estudada de sentidos atuais.

Pensando na formação inicial dos professores de literatura, algumas práticas pedagógicas têm confrontado tal problema, como a que se pôde acompanhar em uma instituição privada da Baixada Santista. A ideia era a de promover a leitura autônoma das obras, a fim de evitar a conhecida prática dos alunos - mesmo os que frequentam os últimos semestres da graduação - de lerem os resumos das obras, as análises prontas, os estudos dirigidos. A proposta foi realizada em "Literaturas africanas de língua portuguesa", componente amparado teoricamente nos estudos dos professores Antonio Candido, Alfredo Bosi e Benjamin Abdala, esse último, como vimos, com uma proposta voltada para o olhar comparado como meio para a superação das práticas pautadas no panorama positivista e descritivo da história da literatura.

A iniciativa partiu de um "retrato" da formação construída até o momento pelos estudantes, capturado na primeira aula do componente curricular a partir de uma sondagem inicial. É preciso valorizar o fato de terem sido selecionados poucos textos teóricos, a fim de deixar tempo para as discussões dos textos literários, os quais foram definidos quase que em sua totalidade pelos alunos, orientados pelo professor.

A partir de uma roda de conversa, estabeleceu-se como ponto de partida "A menina Vitória", do angolano Arnaldo Santos. A leitura prévia e solitária dos alunos levou à leitura de trechos em sala de aula e à discussão do conto sem qualquer objetivo prévio ou estudo dirigido. Posteriormente, os alunos foram orientados a selecionarem um aspecto do conto, para eles significativo, e a pesquisarem alguma outra obra literária - africana, brasileira e/ou portuguesa, que explorasse tal aspecto. A partir disso, os alunos deveriam trazer a obra selecionada, já lida completamente ou não, e indicar as possíveis aproximações e afastamentos entre ambas, contemplando questões históricas, teóricas, estilísticas e até biográficas. Alguns dos textos selecionados foram incorporados às aulas ministradas no semestre letivo, propondo contrapontos e animando o próprio componente curricular.

Seguramente, este exemplo bem-sucedido do ponto de vista da formação do leitor literário, tem problemas e limites, e é um risco, quando se pensa nas provas oficiais, em alguns concursos públicos e na expectativa dos próprios graduandos com relação à sua formação inicial. Também há a dificuldade dos estudantes construírem autonomia para eles mesmos organizarem e sistematizarem a profusão de leituras literárias, o que pode 
ser conseguido por meio da proposição da construção de um portfólio.

Apesar das dificuldades, práticas como essas se constituem como uma brecha para a construção de estratégias que provoquem a experiência literária, para a formação de leitores literários críticos e argutos, para a construção de um largo repertório e, mais do que tudo, para que o professor em formação construa autonomia e liberdade diante do texto literário, a fim de que se complete por meio da literatura a cada vez mais necessária humanização do homem e se realize o "voo" possível do ser humano ao encontro da coletividade, da história e do si mesmo.

\section{CONSIDERAÇÕES FINAIS}

Junto com Candido, com Ligia Chiappini, com Haquira Osakabe, com tantos outros, a perspectiva apontada é a de que a literatura seja ensinada dentro da possibilidade de um profícuo diálogo entre obra e leitores. Enfeixando as discussões realizadas no campo dos estudos literários com as Orientações Curriculares para o Ensino Médio (2006), os modelos de história literária e a concepção de cânone precisam ser flexibilizados, segundo a voz dos alunos que permeia o espaço escolar, a fim de que o professor possa trabalhar com textos que de algum modo impacte os alunos. Mas o professor, como se procurou mostrar, adotará novos modos de lidar com o texto literário em sala de aula e selecionará outros cânones se tiver construído autonomia e liberdade diante das obras, o que só é possível com uma larga e profunda experiência literária. Para tanto, faz-se necessário transformar as práticas pedagógicas adotadas no ensino superior, a partir da ruptura com a concepção de um ensino de literatura sustentado pelos modelos de historiografia literária positivista, pelos eventos literários exteriores à obra, por uma visão limitada dos cânones.

Se é preciso que o professor pense e repense suas práticas a partir da reflexão crítica sobre sua concepção de ensino da literatura, é necessário que ele mesmo experimente plenamente os textos literários ao longo da sua formação inicial - e continuada -, a fim de que se cumpra uma educação literária na dinâmica do cotidiano e na história. A relação entre literatura e ensino se propõe nesse necessário encontro do público com os textos literários, porque só por meio da experiência é que a literatura pode afirmar o diálogo com o passado (lido nos repertórios e nas experiências), com o presente (lido nas teias dos sentidos construídos) e com o futuro (lido na abertura das brechas para que se vislumbre o futuro):

Sendo o objeto da literatura a própria condição humana, aquele que a 
lê e a compreende se tornará não um especialista em análise literária, mas um conhecedor do ser humano. Que melhor introdução à compreensão das paixões e dos comportamentos humanos do que uma imersão na obra dos grandes escritores que se dedicam a essa tarefa há milênios? E, de imediato: que melhor preparação pode haver para todas as profissões baseadas nas relações humanas? Se entendermos assim a literatura e orientarmos dessa maneira o seu ensino, que ajuda mais preciosa poderia encontrar o futuro estudante de direito ou de ciências políticas, o futuro assistente social ou psicoterapeuta, o historiador ou o sociólogo? (TODOROV, 2009, p. 93).

O voo que a educação literária deve proporcionar aos leitores depende da literatura poder desempenhar plenamente sua vocação humanizadora, ao possibilitar ao público a experiência de se tornar um permanente "conhecedor do ser humano". Caso contrário, a literatura estará ao lado de outras mercadorias inúteis, que se impõe no espaço-tempo como mais um entre os muitos obstáculos a serem administrados e os leitores permanecerão às margens da obra e da necessidade de compreendê-la como objeto de fruição vivo, dinâmico e contextualizado, que gera contradições e estabelece a crise. Essa é, ao fim, a concepção de literatura que pode tirar a literatura do limbo e livrá-la do perigo de perder todo o seu potencial revolucionário.

\section{REFERÊNCIAS BIBLIOGRÁFICAS}

INSTITUTO PRÓ-LIVRO. $3^{\text {a }}$ Edição Retratos da Leitura no Brasil. 2011. Disponível em www.prolivro.org.br. Acesso em junho de 2013.

INSTITUTO PAULO MONTENEGRO. Indicador Nacional de Analfabetismo Funcional: um diagnóstico para a inclusão social pela educação. São Paulo: IPM:AE 2005. Disponível em http://www.ipm.org.br/download/inafo5.pdf. Acesso em junho de 2013.

Entrevista com Graça Paulino. http://www.youtube.com/watch?v= 1SQvbhWZCE. Acesso em junho de 2013 .

BRASIL. Secretaria de Educação Fundamental. Parâmetros curriculares nacionais. Ensino Fundamental Secretaria de Educação Fundamental. Brasília: MEC/SEF, 1998.

BRASIL, Secretaria de Educação Média e Tecnológica. Parâmetros Curriculares nacionais. Ensino Médio. Linguagens, Códigos e suas Tecnologias. Brasília, MEC; SEMTEC, 2002.

BRASI. Secretaria de Educação Média e Tecnológica. Orientações Curriculares para o Ensino Médio. Linguagens, Códigos e suas Tecnologias. Brasília, MEC, SEMTEC, 2006.

INEP. Prova Brasil. Disponível em http://sistemasprovabrasil2.inep.gov.br/ Acesso em 
janeiro de 2013 .

ABDALA, Benjamin Jr. História Literária e o Ensino das Literaturas de Língua Portuguesa. In: De Vôos e Ilhas. Literatura e Comunitarismos. São Paulo: Auteliê, 2003.

BOSI, Alfredo. Por um historicismo renovado: Reflexo e reflexão em história literária e “Os estudos literários na era dos extremos". In: Literatura e Resistência. São Paulo, Companhia das Letras, 2002.

CANDIDO, Antônio. A literatura e a formação do homem. In: Revista Ciência e Cultura, v.24, no 9, 1972.

CANDIDO, Antônio. O direito à literatura. In: Vários Escritos. São Paulo/Rio de Janeiro, Duas Cidades, 2004. pp. 169 a 192.

COSSON, Rildo. Letramento literário: teoria e prática. São Paulo: Contexto, 2009.

FREDERICO, Enid Yatsuda e Osakabe, Haquira. "Literatura”. In Orientações Curriculares do Ensino Médio Brasília: MEC/SEB/DPPEM, 2004. http://portal.mec.gov.br/seb/ arquivos/pdf/ozLiteratura.pdf. Acesso em junho de 2013.

FREIRE, Paulo. A importância do ato de ler: em três artigos que se completam. São Paulo: Autores Associados: Cortez, 1989.

GERALDI, João Wanderley. O texto na sala de aula. São Paulo, Ática, 2011.

LEAHY-DIOS, Cyana. Educação Literária como Metáfora Social. São Paulo: Martins Fontes, 2004.

LEITE, L. C. M. Invasão da catedral: literatura e ensino em debate. Porto Alegre: Mercado Aberto, 1983.

PAULINO, Graça. Letramento literário: por vielas e alamedas. Revista da FACED, n.5, 2001.

SILVA, Ezequiel Theodoro da. O Ato de Ler: Fundamentos Psicológicos para uma Nova Pedagogia da Leitura. São Paulo: Cortez Editora, 2002.

TODOROV, Tzvetan. A literatura em perigo. Rio de Janeiro: Difel, 2009. 